\title{
Project Stakeholder Management:A Case Study of a Brazilian Science Park
}

\author{
Antônio Carlos Pacagnella Júnior', Geciane Silveira Porto², Ornella Pacífico², \\ Alexandre Pereira Salgado Júnior ${ }^{4}$
}

\begin{abstract}
The stakeholder management has been a topic increasingly discussed in the literature about project management, though still existing, large gaps to be filled, especially in complex projects such as the implementation of science parks. Thus, in this paper is presented a case of a Brazilian Science Park which shows how the management team of the project identified key stakeholders and established strategies for engagement and collaboration that sought to increase their engagement, get resources and make use of specific capabilities that were required during the lifecycle of the project to the reaching of its goals.
\end{abstract}

Keywords: stakeholders management; science parks; project management; innovation.

'State University of Campinas, Applied Science Faculty, - R. Pedro Zaccaria, I 300, Limeira - São Paulo - Brazil, Zipcode: I 3484-350, E-mail: antonio.junior@fca.unicamp.br (Corresponding author).

2,3,4 University of São Paulo, Faculty of Economics, Administration and Accounting of Ribeirão Preto - Avenida dos Bandeirantes, 3900, Ribeirão Preto, São Paulo - Brazil, Zipcode: 14040-905.

ISSN: 07 I8-2724. (http://www.jotmi.org)

Journal of Technology Management \& Innovation @ Universidad Alberto Hurtado, Facultad de Economía y Negocios. 


\section{Introduction}

The generation of new technologies is critical to the competitiveness of firms, regions and countries, so actions to improve the development of technology have been undertaken by the private sector and by different levels of government. Among these actions, one is noteworthy for its integrative character and for its results obtained in developed countries: the creation of science parks.

In emerging economies, science parks can be considered as catalysts for development, supporting newly created hightech companies and guiding established companies towards innovation in products and processes (Bigliardi et al., 2006).

According to ANPROTEC-ABDI (2008), the mission of a science park is to provide "intelligence", infrastructure, and the services necessary for the growth and strengthening of technology-intensive companies. In a science park, innovative projects aimed at improving this segment are concentrated, connected, organized, articulated, implemented, and promoted.

A science park is a cooperative environment for the development of new scientific knowledge and technologies, integrating in one place high-tech newly created companies (startups), centers of Research and Development (R\&D), universities, and research centers.

According to Guan and Zhao (2013), in this environment there is a synergistic relationship between these actors, with the intensive generation and transfer of technology, and this makes a science park an object of interest to companies and researchers in the field of management.

However, the creation of this environment is complex because it depends on agreements and negotiations between the various actors involved, and it is usually conducted as a project with a dedicated team to mediate between these elements and to do the work of planning and executing the venture.

The creation of a science park is a large project involving a great diversity of actors who have particular interests that may influence its outcome, and this requires a set of specific management actions if it is to be successful: the management of stakeholders.

In the project management field, stakeholder management has increased in relevance in recent years, and this can be seen by its recent inclusion as a knowledge area in the latest version of the Project Management Body of Knowledge (PMBOK), which is possibly the best-known reference in the worldfield.
According to PMI (20/3), stakeholder management in projects includes all the processes required in identifying the people, groups or organizations that may have an impact on or be impacted by the project, analyzing their expectations and their impact on the design, and developing appropriate management strategies for their engagement.

Science parks, according to Paolini et al. (2010), have been widely studied in recent years, but these authors say that the majority of the studies have focused on the economic and technological performance of science parks or on their impact on local development, and that there are still many gaps to be filled on this subject.

Furthermore, Purvis et al. (2014), points out there are few studies related to stakeholder management in projects, which, according to the authors, it is becoming one of the most promising fields for research in this area. Especially when the subject studied provides empirical evidences.

Thus, considering the particular features of projects to create science parks, in relation to the level of engagement of the stakeholders involved and the relevance of the development of a science park for technological development, from a managerial point of view it is crucial to identify those actions that increase the likelihood of success in this type of project. Within this context, the following research question guided the study: "What stakeholder management practices are used in science parks successful projects?"

To answer the research question, a case study aimed at examining the creation of a science park in Brazil was conducted, with special attention being given to the management of stakeholders. The Ribeirão Preto Science Park project was chosen for the study because it is recent and is well-structured, and because the authors had direct access to information regarding its management.

This paper is structured as follows: the first section is the introduction, where the context and the reasons for the choice of the phenomenon in the study are presented, the second and third sections present the theoretical framework that supports the execution of the research, addressing the characteristics of the creation of science parks and stakeholder management respectively, the fourth section highlights the methodological aspects of the work, the fifth section presents the case study results and the sixth section presents the conclusions.

\section{Science Parks}

The traditional model of a science park is based on the concept of a "triple helix", which was initially proposed by Etzkowitz (1993). This model assumes that in a knowledge- 
based society, the potential for innovation and economic development is mainly in the interaction between universities, industry and government.

Thus, science parks can be defined as complexes of economic and technological development that aim to promote knowledge-based economies through the meeting of scientific and technological research, business, and government organizations in one place, offering support to the relations between these players. In addition, science parks may harbor centers for scientific research, technological development, the innovation and incubation of new businesses, training, and research, and may have a formal link with (and are usually physically close to) centers of technological excellence, universities and/or research centers (ABDI, 2008).

The common infrastructure and the tight integration between the actors in a science park lead to a reduction of risks and costs in the development of new technologies. This type of environment encourages the generation and sharing of the knowledge that is produced, and the aim of turning it into applications that have commercial value.
According to Elisa et al. (20I3), the main objective of a science park is to attract companies, create startups, foster development activities and technology transfer and act as a central hub to create internal networking, which is fundamental from a scientific point of view. Jongwanich et al. (2013) argue that science parks play a key role in the coordination of the R\&D efforts of the actors involved, directly contributing to the technological development of the region, and consequently of the country, in which they are located.

The establishment of technology parks is therefore recognized as a strategy for developing high-tech industries, because companies located in these environments tend to be more productive in R\&D than others located outside them (Yang et al., 2009).

The benefits of the creation of a science park are readily observable in successful cases such as Silicon Valley, Route 128 and the Research Triangle Park, all in the United States, Cambridge Science Park in England and the Singapore Science Park in China; however, the implementation project can be complex because of the differences in the interests of the key stakeholders involved, as can be seen in Table I.

\begin{tabular}{|l|l|}
\hline Stakeholders & Primary interests \\
\hline Universities and Research Centers & $\begin{array}{l}\text { To commercialize the results of academic research } \\
\text { in order to broaden the sources of financial re- } \\
\text { sources and expand the labor market for research- } \\
\text { ers and students. }\end{array}$ \\
\hline Entrepreneurs and academic-entrepreneurs & $\begin{array}{l}\text { Take advantage from the results of academic re- } \\
\text { search activities in order to enhance the corporate } \\
\text { R\&D activities. } \\
\text { Improve the financial return. } \\
\text { Access qualified human resources. }\end{array}$ \\
\hline Financial agents and venture capitalists & $\begin{array}{l}\text { Investments in promising technology companies } \\
\text { with high potential for economic growth and rapid } \\
\text { payback. }\end{array}$ \\
\hline Government and development agencies & $\begin{array}{l}\text { Supporting technological innovation activities. } \\
\text { Revitalize economically depressed regions. } \\
\text { Generate jobs. }\end{array}$ \\
\hline
\end{tabular}

Table I. Key stakeholders of a Science Park and primary interests 
Table I shows that the interests of key stakeholders are aligned with regard to the economic and financial exploitation of the science and technology produced in the venture, but that there are important differences: for example, in universities and research centers the focuses are on stimulating scientific development and expanding the market for researchers, for financial agents and venture capitalists the objective is to obtain quick financial returns from their investment, and governments and development agencies have an interest in generating jobs and stimulating the local economy.

For Vedovello et al. (2006), the successful creation of a technology park depends on certain key factors:

- The presence of a minimum infrastructure in residential and business areas, with basic sanitation and urbanization, the availability of transport, and telecommunications;

- Universities / research institutes, with a high degree of excellence, already located in the region where the park will be founded; these will be responsible for training and human resources, such as scientists and engineers, and technical training, and for motivating these people to generate, absorb and diffuse a positive entrepreneurial spirit among their peers and students as well as to support the activities undertaken by the companies;

- The presence of companies, in particular small and medium companies, possessing a culture of innovation, with R\&D activities as the main driver for their activities;

- Entrepreneurship, which emerges as a result of the combination, quality and availability of the local human resources and incorporates a special dynamism that is focused on technological and behavioral changes;

- The provision of financial resources by government, acting as a catalyst in this process through specific programs or the use of its purchasing power, and also by the private sector (companies, commercial banks and venture capitalists).

Other relevant aspects related to the success of a project to establish a science park are described by Hansson (2007). $\mathrm{He}$ highlights the need to stimulate the entrepreneurial culture in universities and other participants by conducting professional development courses, to provide a team with experience in management and always to seek the active involvement of researchers from these institutions in the project.

Cheng et al. (2013) argue that, for a science park to be successfully created, it is very important to create formal and informal relationships of synergy between the project stakeholders, especially between high-tech companies and research centers and universities. These relationships can be fostered by the performance of the project management team.

From a financial perspective, a science park should be attractive to venture investors, so success depends on identifying people and organizations (public and private) who are willing to allocate financial resources to the project, explaining the possible returns that can be obtained from its creation (Haggard \& Zheng, 20I3).

From the arguments cited in this section it can be seen that, if the creation of a science park is to be successful, there must be a balance between the interests of the key stakeholders in order to take advantage of their potential and keep them engaged in the project. This importance leads to a discussion of the literature on stakeholder management in projects, in the next section.

\section{Project Stakeholder Management}

According to Beringer et al. (20|3), stakeholder management is considered, from both a professional and an academic standpoint, to be extremely important for achieving success in projects. For these authors, the stakeholders have a dual relationship with the performance of the project, because their actions can influence the project, but, on the other hand, the results of the project may affect their interests.

From a practical point of view, stakeholder management allows the project leaders to create factors that lead to the effective participation of stakeholders in the project and consequently allow the leaders to reap the benefits of the engagement of the stakeholders with regard to obtaining resources and using their influence (Purvis et al., 2014).

In order to carry out this management, it is necessary to identify the parties whose interests and influence are relevant in the project environment, and to understand the factors that motivate them, seeking to engage with them when possible to generate mutual benefits.

Stakeholder management in a project must also involve an understanding of the behavior of the stakeholders during the life cycle of the project, with the aim of performing actions that meet their expectations (Beringer et al. 2013).

For Alltonen (201 I), the management of stakeholders in a project involves a process of interpretation, which can generate different understandings of the environment surrounding the managerial actions that are subsequently taken. Therefore, the inadequate management of these stakeholders can easily lead to misunderstandings and 
conflicts between them, affecting the success of the project. Considering these aspects, the PMI (2013) proposes that stakeholder management for a project must be conducted through the set of processes illustrated in Figure I.

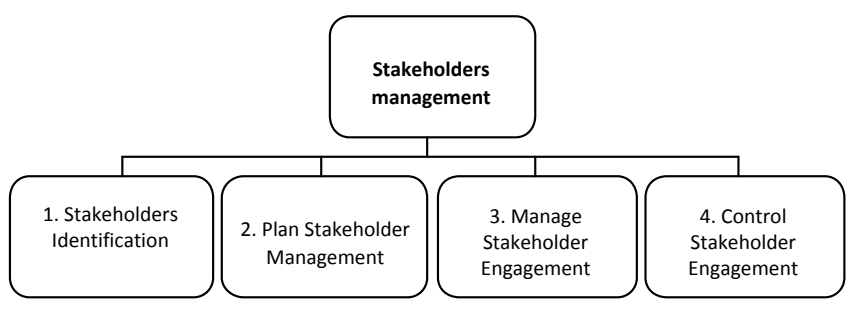

Figure I. Stakeholders management processes according PMI (20I3).

As can be seen in Figure I, the first process for managing the stakeholders in a project involves identifying all persons, groups or organizations that may impact on or be impacted by a decision, activity or result of the project, and analyzing and documenting all relevant information regarding their interests, level of engagement, interdependencies, influence, and potential impact on the success of the project.

The second process, which is shown in Figure $I$, is to plan the management of the stakeholders, by developing appropriate management strategies to engage with them effectively throughout the life cycle of the project, based on a needs analysis, their interests, and their potential impact on the success of the project. The third process is the management of stakeholder engagement; this is related to communication, and requires work to meet the stakeholders' needs and expectations, addressing issues as they occur and encouraging proper engagement. The final process is the control of stakeholder engagement, which aims to monitor the relationships between the project stakeholders in general, adjusting strategies and plans to maintain engagement.

The identification of the stakeholders is critical, and when the level of their power and influence are mapped, their impact on the project can be better understood (Bourne \&Walker, 2005). For Olander \& Landin (2005), the identification of the level of power and interest of each stakeholder allows the stakeholders to be positioned in an array of power/interest, so that the most appropriate management strategy can be chosen, as shown in Figure 2.
From Figure 2 we can see that the classification of the stakeholders makes it possible to obtain a better understanding of the level of effort required for their management, allowing the management team to prioritize their project work as required. For Orlander \& Landin (2005), the identification and classification of the stakeholders is one of the most important issues that should be considered by project managers, to enable them to understand the factors that motivate the stakeholders and the different types of demand they may make.

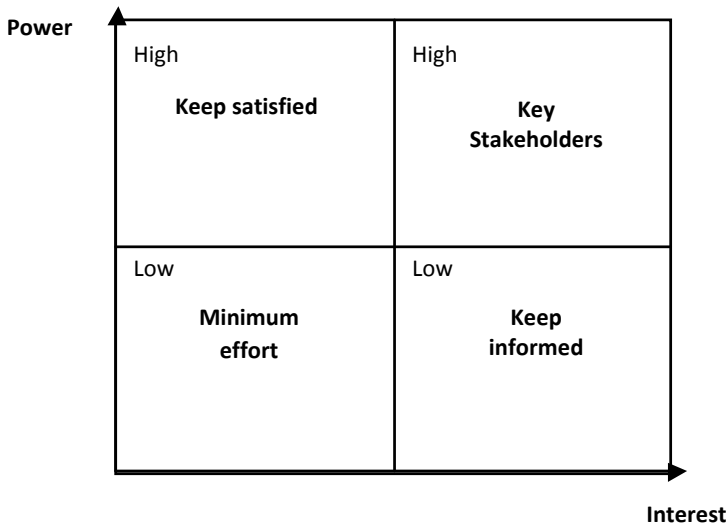

Figure 2. Power / Interest matrix

Clement (2005) suggests that a deeper analysis of stakeholders can be made, according to which it is also possible to understand stakeholders as having three attributes: the first, as highlighted earlier, is their power level, which relates to their ability to impose their will on design decisions; the second is legitimacy, which relates to whether their actions in the project are widely acceptable from a normative or social point of view; and the third is their level of urgency, which means the level of urgency of the efforts that should be undertaken at the solicitation of the stakeholder. Thus, this author proposes the following classification of stakeholders:

- Dormant: have power to impose their will but do not have a legitimate relationship or an urgent demand and therefore have only a latent influence;

- Discretionary: possess legitimacy, but not the power that is necessary to influence whether an urgent demand is met; - Demanding: have urgent demands, but have no power or legitimacy to influence whether their demands are met;

- Dominant: have power and legitimacy. Their influence is ensured by the results when their demands are met;

ISSN: 07I 8-2724. (http://www.jotmi.org) 
- Dependent: have no power, but have urgent demands and the legitimacy to make those demands;

- Dangerous: have urgency and power but no legitimacy, and so can be coercive or dangerous. The use of coercive power often accompanies an illegitimate position;

- Definitive: possess power, legitimacy and urgency, and therefore are the most influential and obviously the most important stakeholders;

- Other: have none of these attributes but can still be affected by actions or the outcomes of the project.

As already highlighted, after identifying and understanding the stakeholders for a project, it is critical to establish strategies aimed at engaging with them, to seize their interest and to take power in this respect. Table 2, based on the proposal of Lim et al. (2005), suggests four generic strategies that can be used.

As can be seen in Table 2, it is possible to establish ways to treat stakeholders that depend on their characteristics and on the need to use their influence positively. As examples, the strategy of collaboration or the strategy of involvement can be interesting when it comes to a stakeholder who has a high level of power and legitimacy (and so is dominant or definitive), while a strategy of monitoring cannot be used when there is an urgent demand but no power (a dormant stakeholder), and the defend strategy can be used when there are pressing demands and power but no legitimacy (dangerous stakeholders).

It should be noted that if the generic strategies presented in Table 2 are to be effective, they must be translated into practical action, and also that there is the possibility of combining strategies to create hybrids that are better adapted to a particular project situation.
Another important aspect to be highlighted is that during the project life cycle stakeholders can change their levels of power, legitimacy and urgency, thus changing their classification. The project team must therefore understand that managing stakeholders requires a continuous monitoring process that can lead to corrections in the planning or execution of the project actions as new positions are detected.

It is specifically large and complex projects, such as the creation of a technology park, that, according Sallinen et al. (20II), are significantly affected by different types of stakeholders. A high level of dedication to the management of stakeholders in these projects is necessary in order to take advantage of their capabilities (stakeholders can be seen as an extension of the project team, or as providing resources) and avoid threats.

\section{Methods}

This section is intended to provide the means to achieve the research objectives, Thus, in order to clarify the methodological approach of this study, it is necessary to classify it, which according to Gil (2002), is very useful for the establishment of a theoretical framework, enabling a conceptual approach to the object of study.

Thus, regarding to the approach, this research can be characterized as qualitative, because has the premise of analyze and interpret deeper aspects, describing the complexity of human behavior and providing even more detailed analysis of the investigations, attitudes and behavioral tendencies. It is also an empirical research, because it searches to analyse a social environment, by collecting data from direct sources who experienced the phenomenon studied.

\begin{tabular}{|l|l|}
\hline Strategy & Definition \\
\hline Colaborate & $\begin{array}{l}\text { Supporting the stakeholders to avoid potential threats and get assistance for } \\
\text { the project activities; }\end{array}$ \\
\hline Envolve & $\begin{array}{l}\text { Present to the stakeholders the potential benefits, seeking to stimulate their } \\
\text { engagement and harness their potential. }\end{array}$ \\
\hline Monitorate & $\begin{array}{l}\text { Observe stakeholders along the project life cycle to verify changes in their } \\
\text { status; }\end{array}$ \\
\hline Defend & $\begin{array}{l}\text { Prepare the project to address any actions of stakeholders seeking to elimi- } \\
\text { nate threats or mitigate their impact. }\end{array}$ \\
\hline
\end{tabular}

Table 2. Strategies to manage stakeholders in projects.

ISSN: 07I 8-2724. (http://www.jotmi.org) 
Regarding to the research method, this paper adopts the case study, which can be characterized, according to DeMarrais \& Lapan (2004), as the one whose object is a unit which is deeply analysed, targeting the detailed examination of an environment, of a subject or of a particular situation. The case study consists of an empirical research that examines the contemporary phenomenon within its context, especially when the boundaries between phenomenon and context are not clearly defined. The steps of the study are shown in figure 3.

The method is based on the proposal of Miguel (2007), but in a simplified form, in four steps: the first consisted of a mapping of the literature on technological parks and stakeholder management in projects, for the purpose of outlining a theoretical framework, in order to establish a theoretical framework. The second step was the planning process that allowed selecting the case to be studied and the data sources. The third step was the data collection trough interviewing the project team members and also readings of project documents. The fourth and last step was the data analyzing which allowed producing a report of the studied phenomena using the found evidence as a basis, as shown in the next section.

\section{The case of Ribeirão Preto Science Park}

The Ribeirão Preto Science Park project was structured through a partnership between the University of São Paulo (USP), the Municipality of Ribeirão Preto, Department of Economic Development, Science, Technology and Innovation of the State of São Paulo, and the Advanced Pole Institute of Health Foundation (FIPASE), with support from the Financier of Studies and Projects (FINEP), the Ministry of Science, Technology and Innovation (MCTI) and the Foundation for Research Support of the State of São Paulo (FAPESP).

Named "SUPERA Innovation and Technology Park of Ribeirão Preto", the development is located on land provided by the University of São Paulo, next to its campus in the city. Its main objective is to create an environment for coexistence and synergy between the university, the government and businesses to undertake research, development and innovation through the installation, at this location, of corporate R\&D units and also production systems focused on innovative products and processes. Its creation aims to boost the scientific and technological development of the region, primarily seeking to attract technology-intensive companies focused on areas such as biotechnology, information technology, and bioenergy, but not to the exclusion of other areas.

The project originated in 2005 from an idea that emerged among managers of FIPASE, and initial contacts were made with the innovation agency of the USP, the State Government of São Paulo and the MCTI.These culminated in a protocol of intent signed in the same year by these stakeholders, the Municipality of Ribeirão Preto, and the Brazilian Agency for Industrial Development (ABDI). From this point, the project was formally part of a state government initiative known as Paulista System of Science Parks that aims to support, develop and integrate the science parks of São Paulo State.

In 2006, the project (reference 4046/05) was approved by the "Ordem de Ação Transversal/72", entitled "Assessment of the implementation strategy of Ribeirão Preto Science Park", signed by FINEP and FIPASE, with a duration of one year. Resources of $R \$ 250,000$ were designated for studies necessary for the project to create the Park.

The project management was then carried out by FIPASE, using a team of about ten people.Although before this point many of the initiatives undertaken could be considered as stakeholder management, from this time onwards it is possible to highlight them.

According to the project management team, planning actions involving studies to identify the technological profile of higher education institutions and research centers in the region and the profile of the business and activities of strategic interest and economic potential were carried out in order to analyze the possible scenarios for land use, with definitions of alternative locations, densities and occupation and the identification of key project stakeholders.

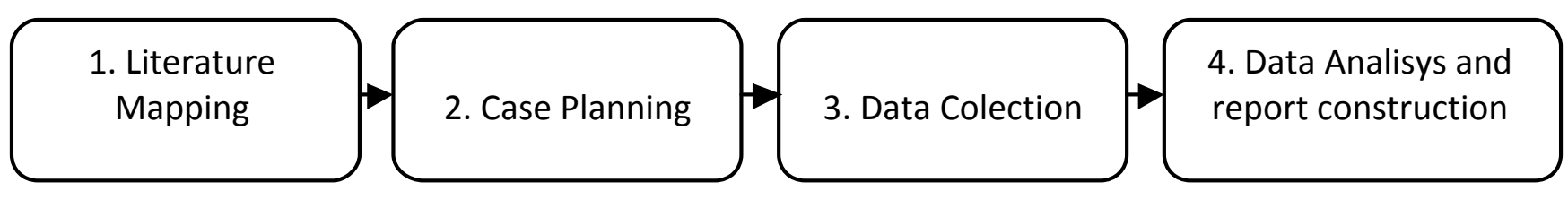

Figure 3. Phases of the case study

ISSN: 07I 8-2724. (http://www.jotmi.org) 
The main stakeholders identified in this process were: FIPASE, the USP, Ribeirão Preto City Government, the Department of Economic Development, Science, Technology and Innovation of the State of São Paulo, the MCTI and private investors (venture capitalists). Table 3 presents a description and a classification of the main stakeholders according to their levels of power and interest.

Table 3 shows that the main stakeholders differ in their levels of interest and power (assuming a range of $\mathrm{I}$ to $\mathrm{I} 0$ for both dimensions). When the level of power is considered, the order of importance from highest to lowest is: the Department of Economic Development, Science, Technology and Innovation of the State of São Paulo, the USP, the Municipality of Ribeirão Preto, the MCTI and FIPASE, and finally the private investors; however, when considering only the level of interest this order changes to: FIPASE, the USP and the Department of Economic Development, Science, Technology and Innovation of the State of São Paulo, the private investors and finally the Municipality of Ribeirão Preto and the MCTI. For a better understanding of this assessment it is possible to put the stakeholders in the matrix proposed by Olander \& Landin (2005).

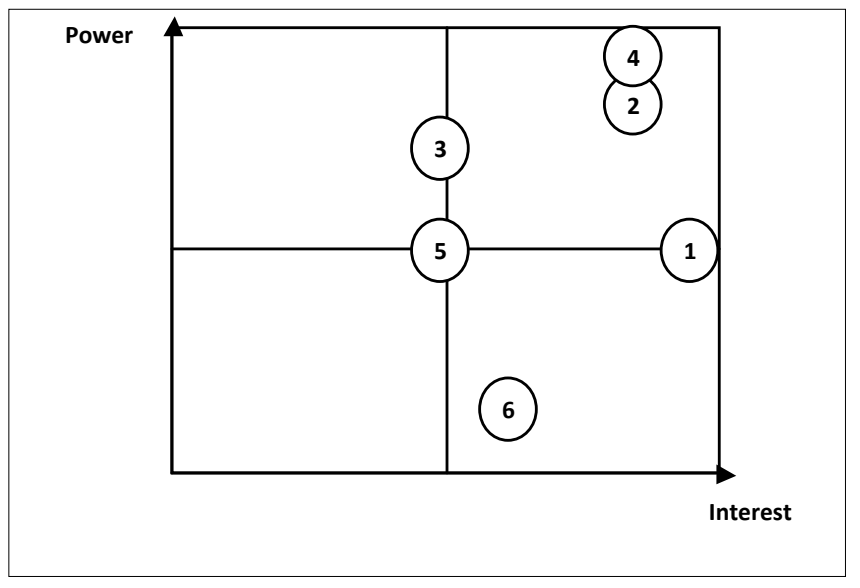

Figure 4. Power/interest matrix (Science Park)
As can be seen from Figure 4, the majority (I, 2, 3, 4 and 5) can be classified as key stakeholders of the project, but the private investors, because they have a low level of power, are in the zone where they should be informed about the progress of the project in order to maintain their engagement (Figure 2).

Having identified the key stakeholders, the project management team established strategies in order to engage with them. At first, the strategy was common to all and can be considered as the "involvement" strategy mentioned in section 3 of this paper.

This strategy was carried out by sensitizing stakeholders through meetings and informal discussions aimed at presenting the potential benefits of the project. Each stakeholder was observed by the team as an element that could contribute with resources or politically to the success of the project, which is what actually occurred.

Within this context, there was the need to obtain a site for the construction of the project, and three scenarios were considered: the first would be based only in a USP area, the second would use part of the area from the USP and part of an area from private investors, and the third scenario would use only an area from private investors. Many negotiations between these stakeholders were therefore conducted to maintain their engagement.

In addition, financial investment was needed, and it was essential for the team to understand how stakeholders could contribute to this. It was found that the investment could come from the MCTI and the Department of Economic Development, Science, Technology and Innovation of the State of São Paulo, and that it should occur through "public notices" at different times during the project.

\begin{tabular}{|l|l|l|l|}
\hline Stakeholder & Interests & Power Level & $\begin{array}{l}\text { Interest } \\
\text { Level }\end{array}$ \\
\hline I. FIPASE & Promote the development of the region & 5 & 10 \\
\hline 2. USP & Foster technology transfer and spin-offs & 9 & 8 \\
\hline 3. Municipality of Ribeirão Preto & $\begin{array}{l}\text { Generate jobs and collect taxes on the project and } \\
\text { established firms }\end{array}$ & 8 & 5 \\
\hline $\begin{array}{l}\text { 4. Dept. of Econ. Dev., Science, Technology } \\
\text { and Innovation of the State of São Paulo }\end{array}$ & $\begin{array}{l}\text { Create a network of technology parks in the State of } \\
\text { São Paulo }\end{array}$ & 10 & 8 \\
\hline 5. MCTI & Promote the technological innovation in the country & 5 & 5 \\
\hline 6. Private Investors & Real estate development and return on investment & I & 7 \\
\hline
\end{tabular}

Table 3. Description and classification of key stakeholders regarding Power and Interest levels.

ISSN: 07 I8-2724. (http://www.jotmi.org) 
There was also the need for the presence of an anchor university with a strong presence in research to catalyze the scientific and technological development, the main goal of the park. The USP was therefore treated as a stakeholder that could contribute not just physical resources, but also intellectual resources, and so, in order to harness its skills, its main areas of research (principally in the biotechnology and health fields) were mapped, and influenced the characteristics of the Science Park.

Another aspect related to stakeholder management that may be considered critical to the success of the project was the understanding from the beginning that FIPASE should be the motivator of the other parties in order to achieve the project goals, so the main engagement actions came from their team throughout the project.

During its life cycle, the science park project produced other scenarios, so it was necessary to establish different strategies. An important fact that illustrates this statement occurred in 2008, when there was a final decision regarding the configuration of the Park area, which would be entirely land from the USP. The team sought to keep the private investors, who were initially interested in obtain profits from the real estate development in the region, engaged, using a defending strategy that mitigated the impact of these changes, so that other possibilities for return were presented. This permitted the private investors to stay with the project for another year, until 2009, but after this these investors finally left the project.

At this moment the project was in the final stages of planning, and changes in the predicted scenario had required a change in strategy, with a greater focus on collaboration.

With an understanding of the need for this new strategy, an intensification of the negotiations between the project team and the stakeholders took place, resulting in a meeting between the then Rector of the USP and the Mayor of Ribeirão Preto to discuss a proposal for building a business incubator and technology center in the Science Park, as well as the inclusion in the USP strategic plan (PPA-PMRP 20I02013) of budgeted funds for investments in the Science Park. Another important result of these actions occurred in 2010 when the Secretary of Economics, Science and Technology of the State of São Paulo approved the Science Park project, providing resources for the construction of the first phase of the project.
Also in 2010, there was another successful stakeholder management action for the project that is worth mentioning: the Pro-Rector of the USP made available an attorney with the power to perform all legal modeling for the Science Park and to solve any legal problems that had occurred or could arise in the project.

The support of the Pro-Rector of Research at the USP was essential for allowing the project to continue, and after he had done this a task force was established that worked for four months with weekly meetings to solve the legal problems. This culminated in 2013 with bids for the construction of the infrastructure and buildings of the Science Park, which was opened in 2014, as well as an agreement on the formal structure for the Park and the entire organizational structure for its management.

The project team members also point out that, for stakeholder management, it is necessary not only to identify the technical reasons that could serve as convincing factors to engage the stakeholders, but also to carry out an in-depth study about the subliminal reasons that could motivate each stakeholder to get involved with the project, which are elements that are often understood only in the final phase of the project.

Currently the "Supera Innovation and Technology Park of Ribeirão Preto" is in its final stage of creation and already possesses much of its complete physical structure: the buildings of the business incubator and the Centre for Development and Applied Innovation (CEDINA) have already been completed, and an announcement of the first companies to be installed and to begin their operations is awaited.

\section{Conclusions}

This study was conducted to answer the following research question: "What stakeholder management practices are used in successful projects to create science parks?"

To answer this research question a case study was carried out on the " SUPERA Innovation and Technology Park of Ribeirão Preto " project located in the city of Ribeirão Preto, São Paulo State, Brazil.

It was found that the project team was concerned from the beginning to understand the interests of the main stakeholders and to learn how these stakeholders could contribute to the success of the project. It was also noted that the project team had an interest in exploiting the features and specific capabilities of the main stakeholders, because the project was large and complex and could require different kinds of contributions. 
Another important element that was identified regarding stakeholder management in this type of project was the types of actions of involvement and collaboration that were established; these coincided with the strategies cited from the literature on project management outlined in section 3 of this work.

However, it was revealed that many of these actions were not formally structured, but were conducted by members of the project team because they perceived the need to motivate stakeholders to keep their engagement or support in specific situations during the life cycle of the project. It was also found that the team maintained a constant monitoring of stakeholder engagement and a proactive approach towards changing strategies when necessary.

Another relevant finding regarding the management of the stakeholders was the central position occupied by FIPASE, working as a recognized mediator; its power, legitimacy and sense of urgency turned it into a definitive stakeholder, according to the classification proposed by Clement (2005). Among the limitations found during the research was that it was not possible to collect data directly from all the main stakeholders of the project, because of logistical complexity and the unavailability of some of them. This data could have provided more details and new insights on how the phenomenon of the study occurred.

For future works, the authors suggest that surveys are conducted about the perception of those who are involved in the project about stakeholder management, with a subsequent analysis to quantify the contribution of each of their actions to the project's success. Case studies could even be conducted that compare stakeholder management in the creation of successful science parks with stakeholder management in the creation of others with poor performance, possibly leading to a set of specific best practices for this type of project.

\section{References}

ANPROTEC-ABDI (2008). Parques Tecnológicos no Brasil - Estudo, Análise e Proposições. http://www.abdi.com.brl [Acessed October 10, 20I4].

AALTONEN, K. (20II) Project stakeholder analysis as an environmental interpretation process. International Journal of Project Management. 29(2), I65- 183.

BERINGER, C., Jonas, D. Kock,A. (20I3). Behavior of internal stakeholders in project portfolio management and its impact on success. International Journal of Project Management, v. $3 I(6), 830-846$.

BIGLIARDI, B.; Dormio, A. I.; Nosella, A.; Petroni, G. (2006). Assessing science parks' performances: directions from selected Italian case studies, Technovation, 26(4), 489-505

BOURNE, L.;Walker, D.,H.,T. (2005).Visualising and mapping stakeholder influence, Management Decision, 43(5), 649-660.

CHENG, F;; Oort, F. V.; Geertman, S.; Hooimeijer, P. (20I3). Science Parks and the Co-location of High-tech Small- and Medium-sized Firms in China's Shenzhen. Urban Studies, $5 \mathrm{I}(5), \mathrm{I}-\mathrm{I} 3$.

CLEMENT, R.W. (2005). The Lessons from Stakeholder Theory for U.S. Busines Leaders. Business Horizons, 48(I), 255-264.

DEMARRAIS, K., B.; Lapan, S., D. (2004). Foundations for Research Methods of Inquiry in Education and the Social Sciences. Mahway, NJ: Lawrence Erlbaum Associates Inc.

ELISA S.; llaria, M., Fabrizio, C. (2013). Science park or innovation cluster? Similarities and differences in physical and virtual firms' agglomeration phenomena. International Journal of Entrepreneurial Behaviour \& Research, (19) 6, I-19.

ETZKOWITZ, H. (1993). Technology transfer: the second academic revolution. Technology Access Report, 6(I), 7-9.

GIL. A. C. (2002). Como elaborar projetos de pesquisa. São Paulo:Atlas.

GUAN A.B.; Zhao Q. B. (2013). The impact of universityindustry collaboration networks on innovation in nanobiopharmaceuticals. Technological Forecasting \& Social Change, 80(7), I27I-I286.

ISSN: 07 I 8-2724. (http://www.jotmi.org) 
HAGGARD, S.; Zheng, Y. (20/3). Institutional innovation and investment in Taiwan: the micro foundations of the developmental state, Business and Politics, I5(4), 435-466.

HANSSON, F. (2007). Science parks as knowledge organizations - the "ba" in action? European Journal of Innovation Management, I0(3), 348-366.

JONGWANICH, J.; Kohpaiboon, A.; Yang, C.H. (20I4). Science park, triple helix, and regional innovative capacity: province-level evidence from China. Journal of the Asia Pacific Economy, 19(2), 333-352.

KERZNER, H. R. (2013). Project Management: A Systems Approach to Planning, Scheduling, and Controlling, Hoboken: Jon Wiley \& Sons.

LIM, G.; Ahn, H.; Lee, H. (2005). Formulating strategies for stakeholder management: a case based reasoning approach. Expert Systems with Applications, 28(2), 83 I-840.

MIGUEL, P. A. C. (2007). Estudo de caso na engenharia de produção: estruturação e recomendações para sua condução. Revista Produção, 17(I), 216-229.

ORLANDER, S.; Landin, A. (2005). Evaluation of stakeholder influence in the implementation of construction projects. International Journal of Project Management, 23(I), 32I-328.

PMI (20/3). A guide to the project management body of knowledge, 5th Edition, Newton Square: Pennsylvania.

PURVIS, R. L.; Zagenczik, T. J.; Mcgray, G. E. (20I4). What's in it for me? Using expectancy theory and climate to explain stakeholder participation, its direction and intensity. International Journal of Project Management, 34 (5), 432444.

SALLINEN, L.; Ruuska, I.;Ahola,T. (20I3). How governmental stakeholders influence large projects: the case of nuclear power plant projects. International Journal of Managing Projects in Business, 6(I), 5I-68.

VEDOVELLO, C.; Judice, V.; Maculan, A. M. (2006). Revisão crítica às abordagens a Parques Tecnológicos: alternativas interpretativas às experiências brasileiras recentes. Revista de Administração e Inovação, 3(2), 103-I 18.

YANG, C.; Motohashi, K.; Chen, J.R. (2009). Are new technology-based firms located on science parks really more innovative? Evidence from Taiwan. Research Policy, 38(I), 77-85. 